ACADEMIA ROMÂNĂ
Rev. Roum. Chim.,
Revue Roumaine de Chimie
http://web.icf.ro/rrch/

\title{
DETERMINATION OF TRYPTOPHAN IN PHARMACEUTICAL FORMULATIONS AND BEER BY ENHANCEMENT OF TRYPTOPHAN-FLUORESCENCE RESPONSE WITH FLUORESCEIN AND POTASSIUM HEXACYANOFERRATE(III)
}

\author{
Jacobus Frederick VAN STADEN* ${ }^{*}$ and Ramona GEORGESCU STATE
}

Process Analytical Technology Laboratory (PATLAB) Bucharest, National Institute of Research and Development for Electrochemistry and Condensed Matter (INCDEMC), 202 Splaiul Independentei Str., Bucharest 060021, Roumania

Tryptophan is an essential amino acid for humans with a significant role in cell metabolism. Depletion of tryptophan in the human body may contribute to diseases and development of disorders in humans. The native fluorescence of tryptophan alone was, however, not very sensitive enough in our studies resulting in a limitation of reliability and sustainability of tryptophan analysis. We found that fluorescein as fluorescent dye and potassium hexacyanoferrate(III) as oxidant successfully enhanced the tryptophan-fluorescence response signal to such an extent that a novel proposed enhancement tryptophanfluorescence method with modification using these inexpensive reagents was successfully applied for the determination of tryptophan in pharmaceutical capsules and beer with very good recoveries and relative standard deviation. The recoveries agreed very well with the certified amount labeled for tryptophan in pharmaceutical formulations with very good recoveries between 99.9 and $102.8 \%$ and a relative standard deviation of less than $0.5 \%$

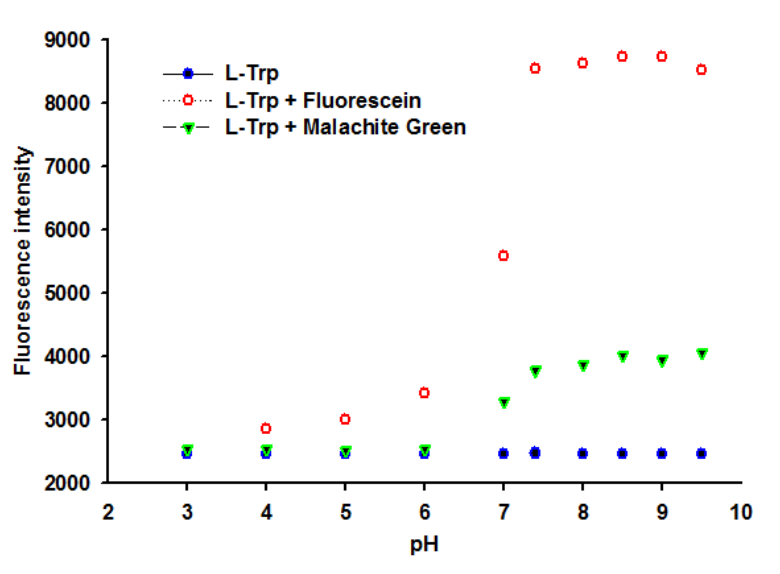
$(n=5)$. The recoveries for the determination of tryptophan in beer were between 93.7 and $95.1 \%$ with a relative standard deviation of less than $0.5 \%(n=5)$.

\section{INTRODUCTION}

Tryptophan, IUPAC name (2S)-2-amino-3-(1Hindol-3-yl)-propionic acid, Trp is an essential amino acid for humans with a significant role in cell metabolism as a protein building block and a precursor for serotonin (a neurotransmitter), ${ }^{1,2}$ melatonin (a neurohormone), ${ }^{3}$ and niacin. ${ }^{4}$ The depletion of tryptophan in the human body may result in low levels of serotonin that may cause fluctuation in the mood, sleep, drowsiness, depression, aggression and in blocking the analgesic effect of morphine. ${ }^{5}$
Deficiency of tryptophan has also been associated with Alzheimer Disease (AD). It was shown that an increase in tryptophan consequently leads to a potential increase in serotonergic 5-HT neurotransmission that may be effective in reducing plaque pathology in $\mathrm{AD} .{ }^{6}$ On the other hand, toxic products generated in the brain by improper metabolism, such as the Kynurenine pathway metabolites, of tryptophan may contribute to diseases and disorders development, like hallucinations and delusions. ${ }^{5-8}$

So far several analytical methods and techniques such as voltammetry, ${ }^{9-11}$ High-Performance Liquid

\footnotetext{
*E-mail: koosvanstaden2012@yahoo.com; Website: www.patlab.ro; Tel.: +40 748137871
} 
Chromatography (HPLC), ${ }^{12-14}$ liquid chromatography-tandem mass spectrometry, ${ }^{15}$ spectrophotometry ${ }^{16}$ spectrofluorometry ${ }^{17}$ and capillary electrophoresis ${ }^{18}$ have been widely used for the detection and quantification of tryptophan in different types of samples. A number of chemiluminescence methods have also been exploited for the determination of tryptophan. ${ }^{19,20}$

Tryptophan is an important intrinsic fluorescent substance (amino acid). It is possible to use these properties to estimate the microenvironment nature of tryptophan in a possible assay of tryptophan. Most of the intrinsic fluorescence emissions of a folded protein are due to excitation of tryptophan residues, $\left(\lambda_{\mathrm{EX}} \sim 280 \mathrm{~nm}, \lambda_{\mathrm{EM}} \sim 350 \mathrm{~nm} ; \lambda_{\mathrm{EX}}=\right.$ excitation wavelength and $\lambda_{\mathrm{EM}}=$ emission wavelength). Therefore a number of publications report work that either exploits or studies tryptophan in proteins. ${ }^{21-26}$ Among the properties used, are changes in fluorescence intensity, wavelength maximum $\left(\lambda_{\max }\right)$, band shape, anisotropy, fluorescence lifetimes, and energy transfer. They are applied to folding/ unfolding, substrate binding, external quencher accessibility, solvent exposure of the chromophore etc. $^{21}$ The mechanisms of tryptophan fluorescent shifts in proteins have been studied in detail by Vivian and Callis ${ }^{21}$ showing the complexity surrounding the microenvironment of tryptophan fluorescence and by Schifferer-Waritschlager. ${ }^{25}$ Furthermore a donor chromophore in its excited state can transfer energy to an acceptor chromophore in a dynamic quenching mechanism called Förster (or Fluorescence) Resonance Energy Transfer (FRET) with quenching the basis of FRET assays. This nonradiative transfer can be described by a dipole-dipole coupling of the chromophores. Effective energy transfer depends on the distance of the two chromophores (usually less than $10 \mathrm{~nm}$ ) and on the Förster Radius $\mathrm{R}_{0}$. $\mathrm{R}_{\mathrm{o}}$ describes the distance between the donor and acceptor at which $50 \%$ of the excited state energy is transferred from the donor to the acceptor. ${ }^{25}$ Usually, the presence or absence of target molecules is monitored by an increase or decrease in fluorescence intensity of one dye interacting via short-range electronic or long-range dipole-dipole interactions with a second dye. Deteriorations of the interaction geometry or efficiency are caused, for example, by specific binding or cleavage events. Especially, the use of FRET between a donor, D, and an acceptor dye, A, has increased considerably in the field of biodiagnostics during the past decade. ${ }^{23}$ It were also clear from these publications ${ }^{21-26}$ that the fluorescence of fluorescein in the presence of tryptophan is a very complex process. Typically, tryptophan is quite sensitive at a maximum excitation wavelength $\left(\lambda_{\mathrm{EX}}\right)$ of $280 \mathrm{~nm}$ and an emission peak that is solvatochromic ranging from around 300 to $360 \mathrm{~nm}$ depending on the polarity of the local environment. However, the native fluorescence of tryptophan alone is not very sensitive and this limits the reliability, stability and sustainability of analytical methods for the determination of tryptophan.

We realized from the description of the intrinsic fluorescence properties of tryptophan above and the execution of preliminary experiments that the response of native fluorescence of tryptophan alone was not suitable enough for our main purpose to find a proper determination of tryptophan in the pharmaceutical formulations and beer samples we have. In this paper we therefore investigate a number of selective fluorescent dyes and oxidants to increase and optimize the response signal of tryptophanfluorescence for suitable determination of tryptophan in a sequence of experiments. We eventually found that fluorescein as fluorescent dye and potassium hexacyanoferrate(III) as oxidant successfully enhanced the tryptophan-fluorescence response signal at $\mathrm{pH}=7.4$ sufficiently for the determination of tryptophan in pharmaceutical capsules and beer with very good recoveries and relative standard deviation.

\section{EXPERIMENTAL}

\section{Reagents and materials}

All reagents were of analytical grade and solutions were prepared using deionized water obtained from a Direct-Q 3 Water Purification system (Millipore Corporation, France).

L-Tryptophan, Alizarin Red S, Crystal Violet, Rhodamine $\mathrm{B}$, Malachite Green chloride, potassium chlorate $\left(\mathrm{KClO}_{3}\right)$, potassium periodate $\left(\mathrm{KIO}_{4}\right)$, potassium hexacyanoferrate (III) $\left(\mathrm{K}_{3} \mathrm{Fe}(\mathrm{CN})_{6}\right)$, sodium phosphate monobasic monohydrate $\left(\mathrm{NaH}_{2} \mathrm{PO}_{4} \cdot \mathrm{H}_{2} \mathrm{O}\right)$, sodium phosphate dibasic heptahydrate $\left(\mathrm{Na}_{2} \mathrm{HPO}_{4} \cdot 7 \mathrm{H}_{2} \mathrm{O}\right)$ and dimethylsulfoxide (DMSO) were purchased from Sigma-Aldrich. Fluorescein and Luminol were obtained from Fluka.

Different phosphate buffer solutions (PBS, $0.1 \mathrm{~mol} / \mathrm{L}$ ) with $\mathrm{pH}=3-9.5$ were prepared using different ratios between $\mathrm{NaH}_{2} \mathrm{PO}_{4}$ and $\mathrm{Na}_{2} \mathrm{HPO}_{4}$. The $\mathrm{pH}$ was adjusted with $0.1 \mathrm{~mol} / \mathrm{L}$ $\mathrm{HCl}$ or $\mathrm{NaOH}$ solutions to the required $\mathrm{pH}$ needed in the measurements.

The stock solution of tryptophan $\left(1.00 \times 10^{-2} \mathrm{~mol} / \mathrm{L}\right)$ was prepared by dissolving $0.1021 \mathrm{~g}$ of L-Tryptophan in $50 \mathrm{~mL}$ of deionized water. The solution was kept in the refrigerator at 4 ${ }^{\circ} \mathrm{C}$ and was protected from light. Working solutions were prepared daily by appropriate dilution of the stock solution with phosphate buffer solutions of different $\mathrm{pHs}$.

Appropriate individual stock solutions for each of the following dyes, Alizarin Red S, Crystal Violet, Luminol, Rhodamin B, Malachite Green and Fluorescein were prepared for preliminary testing. Some of the dyes unfortunately did not 
give any positive results, were therefore not further evaluated and the following optimized solutions were prepared for those that were positive. A $1.00 \times 10^{-2} \mathrm{~mol} / \mathrm{L}$ Malachite Green chloride stock solution was prepared by dissolving $0.036 \mathrm{~g}$ of Malachite Green chloride in $10 \mathrm{~mL}$ of water. The working solution of Malachite Green chloride $\left(1.00 \times 10^{-3} \mathrm{~mol} / \mathrm{L}\right)$ was prepared by direct dilution of the stock solution with phosphate buffer solutions of different $\mathrm{pHs}$.

A stock solution of fluorescein $\left(1.00 \times 10^{-2} \mathrm{~mol} / \mathrm{L}\right)$ was prepared in DMSO. The standard working solution of fluorescein $\left(1.00 \times 10^{-3} \mathrm{~mol} / \mathrm{L}\right)$ was prepared from the stock solution by serial dilution and buffered with phosphate buffer of different pHs.

The stock solutions of potassium chlorate, potassium periodate and potassium hexacyanoferrate $\left(1.00 \times 10^{-2} \mathrm{~mol} / \mathrm{L}\right)$ were prepared in water. The working solutions of potassium chlorate, potassium periodate and potassium hexacyanoferrate were prepared from the stock solutions with $\mathrm{PBS} \mathrm{pH}=7.4$.

\section{Apparatus}

The fluorescence measurements were done with a spectrometer QE65000 from Ocean Optics (Dunedin, Florida) equipped with a xenon lamp (HPX 2000). The HPX-2000 Xenon Light Source is a high-power, high-intensity source that is especially useful for fluorescence applications and for other applications where a high-intensity lamp is necessary. The 35-watt, short-arc lamp supplies a continuous spectrum from the UV through the NIR (185-2200 nm). The HPX-2000 features an integrated shutter that can be controlled via switch or TTL signal. The QE65000 Scientific-grade Spectrometer is a very sensitive spectrometer. The Hamamatsu FFT-CCD detector used in the QE65000 provides 90\% quantum efficiency (defined as how efficiently a photon is converted to a photo-electron) has a detector range $200-1100 \mathrm{~nm}$, and full scans to memory every $7 \mathrm{~ms}$ with USB 2.0 port as data transfer rate. Results are acquired and processed using a Spectra Suite software program. The $\mathrm{pH}$ measurements were performed using a CyberScan PCD 6500 Multiparameter.

\section{Sample Preparation}

Five pharmaceutical capsules of Product $\mathrm{T}$ purchased from a local pharmacy were used. Each capsule contains 1.5\% (15 $\mathrm{mg} / \mathrm{mL}$ ) tryptophan and other excipients. The weight of powder in a capsule was approximately 0.35 grams. The powder from each capsule was inserted in a $100 \mathrm{~mL}$ volumetric flask and was dissolved in deionized water to the mark to give a stock solution. After stirring for a few minutes, the solutions were carefully filtered through a $0.2 \mu \mathrm{m}$ poresize filter to isolate the insoluble excipients. The stock solutions were diluted with $\mathrm{PBS} \mathrm{pH}=7.4$ to obtain the working solutions with the concentration of tryptophan within the range of the calibration curve. Beer sample solutions were diluted with PBS to obtain working solutions at a $\mathrm{pH}=7.4$ with the concentration of tryptophan within the range of the standard working solutions.

\section{RESULTS AND DISCUSSION}

Preliminary experiments showed that the native fluorescence of tryptophan alone was not very sensitive and it was very difficult to observe reliable emission signals. This observation limited the purpose of our study to develop a reliable and sustainable analytical method for the determination of tryptophan. We therefore investigated various possibilities with a strategic study and evaluation to change the properties of tryptophanfluorescence in such a way to obtain suitable sensitive response signals. Preliminary tests were first done with a number of selected dyes such as Alizarin Red S, Crystal Violet, Luminol, Rhodamin B, Malachite Green and Fluorescein together with tryptophan by varying the concentrations and $\mathrm{pH}$ of the solutions of tryptophan with each of the individual dyes. The results shows that a $\mathrm{pH}=7.4$ in phosphate buffer solutions gave the best preliminary observations and was therefore selected for further work. The following results were further obtained with buffered solutions: $1 \times 10^{-2}-1 \times 10^{-7} \mathrm{~mol} / \mathrm{L}$ tryptophan solutions alone that gave emission intensity counts of around $2465 \pm 5$ at a wavelength of $350.4 \mathrm{~nm}$. For a solution of $1 \times 10^{-4}$ $\mathrm{mol} / \mathrm{L}$ Alizarin Red $\mathrm{S}$ the intensity counts were around 2570 at $437.6 \mathrm{~nm}$. A very small quenching effect from 2522 intensity counts for $10^{-7} \mathrm{~mol} / \mathrm{L}$ tryptophan to 2482 intensity counts for $10^{-2} \mathrm{~mol} / \mathrm{L}$ tryptophan in solution of $1 \times 10^{-4} \mathrm{~mol} / \mathrm{L}$ Alizarin Red S were found at a $437.6 \mathrm{~nm}$. The tryptophan emission spectrum at $350.4 \mathrm{~nm}$ disappeared, or was probably so much weaker or the tryptophan fluorescence was shift to $437.6 \mathrm{~nm}$. For a solution of $1 \times 10^{-3} \mathrm{~mol} / \mathrm{L}$ Crystal Violet the intensity counts were around 2438 at $416 \mathrm{~nm}$ that remained more of less the same with different solutions of tryptophan. In the case of a $1 \times 10^{-3} \mathrm{~mol} / \mathrm{L}$ luminol solution, the intensity counts were around 2490 at $425 \mathrm{~nm}$ that was also remaining more or less the same with different solutions of tryptophan. A similar type of observation was obtained for a solution of $1 \times 10^{-3} \mathrm{~mol} / \mathrm{L}$ Rhodamine $\mathrm{B}$ where the intensity counts were around 2729 at $627 \mathrm{~nm}$, but it changed to intensity counts around 3330 at $619 \mathrm{~nm}$ for different solutions of tryptophan. We found that Malachite Green and Fluorescein did not only have an effect on maximum emission wavelength $\left(\lambda_{\max }\right)$ changes, but the change in fluorescence intensity was more obvious. In the case of Malachite Green the quenching effect was, however, not constant and reliable giving the impression that kinetics and fluorescence lifetimes, play a larger role. Very good results were, however, obtained for fluorescein where the intensity counts for tryptophan solutions of $10^{-2}-10^{-7} \mathrm{~mol} / \mathrm{L}$ jumped to between 6970 to 8800 intensity counts at wavelength maximum $\left(\lambda_{\max }\right)$ of $535 \mathrm{~nm}$ in a solution of $10^{-3} \mathrm{~mol} / \mathrm{L}$ fluorescein indicating a relatively large quenching effect with a very good observable emission response signal. 


\section{Effect of pH}

It was therefore decided to proceed with a more intensive study of the influence of $\mathrm{pH}$ on the fluorescence response signal for Malachite Green and Fluorescein. For the determination of the optimum $\mathrm{pH}$, accurate concentrations of standard $10^{-4} \mathrm{~mol} / \mathrm{L}$ L-tryptophan alone and with respectively $10^{-3} \mathrm{~mol} / \mathrm{L}$ Malachite Green and $10^{-3} \mathrm{~mol} / \mathrm{L}$ Fluorescein solutions with the $\mathrm{pH}$ values between 3 and 9.5 buffered with PBS in deionized water were studied. As shown from the fluorescence intensities (counts) plotted against pH (Fig. 1), the fluorescence intensity of tryptophan alone remains almost constant at around $2465 \pm 5$ at a wavelength of $350.4 \mathrm{~nm}$. For tryptophan with Malachite Green the fluorescence intensity (counts) remains constant at a value of around 2500 at a wavelength of $464 \mathrm{~nm}$ in the $\mathrm{pH}$ range 3-6, but starts to increase in values from 3772 at $\mathrm{pH}=7.4$ to 4053 at a $\mathrm{pH}=9.5$, but this value was however not significant enough to be used for reliable and sustainable measurements. It is clear from the results in Fig. 1 that in the case of tryptophan with fluorescein the increase in fluorescent intensity (counts) at a $\mathrm{pH}=7.4$ to around 8548 indicates a very good observable emission response signal for reliable and sustainable measurements and this $\mathrm{pH}$ with fluorescein as fluorescence dye was chosen for further experimental work.

\section{Influence of tryptophan concentration on fluorescein dye at $\mathbf{p H}=7.4$}

According to various publications ${ }^{21-26}$ the native fluorescence of tryptophan alone was not very sensitive and it was very difficult to observe reliable emission signals at a $\mathrm{pH}$ of 7.4. This was confirmed by our experiments where emission intensity counts of around $2465 \pm 5$ were obtained at a wavelength of $350.4 \mathrm{~nm}$ for buffered tryptophan solutions alone with concentrations ranging between $1 \times 10^{-2}-1 \times 10^{-7} \mathrm{~mol} / \mathrm{L}$. Interesting results were however revealed when the overlay fluorescence spectra solution of $10^{-3} \mathrm{~mol} / \mathrm{L}$ fluorescein alone was compared with the overlay fluorescence spectra solutions of different concentrations of tryptophan between $10^{-3}$ to $10^{-6}$ $\mathrm{mol} / \mathrm{L}$ at wavelength maximum $\left(\lambda_{\max }\right)$ of $535 \mathrm{~nm}$ at a $\mathrm{pH}$ of 7.4. The results in Fig. 2 revealed the following information: (i) Due to the large increase in the fluorescence intensity (counts) for tryptophan solutions of $10^{-3}-10^{-6} \mathrm{~mol} / \mathrm{L}$ in a solution of $10^{-3} \mathrm{~mol} / \mathrm{L}$ fluorescein, it seems that $\lambda_{\max }$ of $350.4 \mathrm{~nm}$ for tryptophan alone became less observable and shifted to an observable wavelength maximum $\left(\lambda_{\max }\right)$ of $535 \mathrm{~nm}$. (ii) The fluorescence intensity (counts) of a solution of $10^{-3}$ $\mathrm{mol} / \mathrm{L}$ fluorescein were only 4520 as indicate by the curve from Fig. 2a. (iii) With the introduction of a solution of $10^{-6} \mathrm{~mol} / \mathrm{L}$ tryptophan in a solution of $10^{-3} \mathrm{~mol} / \mathrm{L}$ fluorescein, the fluorescence intensity counts jumped to a large value of 8700 due to a relatively high fluorescence resonance energy transfer (FRET) in the interaction between tryptophan and fluorescein as shown by the curve in Fig. 2b. (iv) It is also clear that the fluorescence intensity (counts) decreased with an increase of tryptophan concentration from $10^{-6} \mathrm{~mol} / \mathrm{L}$ to $10^{-3}$ $\mathrm{mol} / \mathrm{L}$ as seen from the curves in Figs. $2 \mathrm{c}$ to $2 \mathrm{~d}$ to $2 \mathrm{e}$ due to lower FRET in the interaction between tryptophan and fluorescein. (v) Furthermore the relative interactions between different concentrations of tryptophan and fluorescein is indirect proportional to the increase in fluorescence intensity values with decreasing concentrations from $10^{-3} \mathrm{~mol} / \mathrm{L}$ to $10^{-6} \mathrm{~mol} / \mathrm{L}$ of tryptophan solutions as shown in Fig. 3 revealing a linear concentration range between $10^{-6} \mathrm{~mol} / \mathrm{L}$ to $10^{-3}$ $\mathrm{mol} / \mathrm{L}$ with a correlation coefficient of 0.999 . (vi) The results obtained confirmed information from the observations in previous publications. ${ }^{21-26}$

\section{Contribution of oxidants}

Further experimental work was performed to see if selected oxidants $\left\{\mathrm{KClO}_{3}, \mathrm{KIO}_{4}\right.$ and $\left.\left.\mathrm{K}_{3} \mathrm{Fe}(\mathrm{CN})_{6}\right)\right\}$ are able to enhance the fluorescence intensity of tryptophan-fluorescein solutions more. Results obtained showed that $\mathrm{KClO}_{3}$, and $\mathrm{KIO}_{4}$ did not have any significant influence. It was however clear from Fig. 4 that a solution of $10^{-5} \mathrm{~mol} / \mathrm{L}$ $\mathrm{K}_{3} \mathrm{Fe}(\mathrm{CN})_{6}$ gave good accountable enhancement results with a solution of $10^{-3} \mathrm{~mol} / \mathrm{L}$ fluorescein and different concentrations of tryptophan ranging from $10^{-3}$ to $10^{-6} \mathrm{~mol} / \mathrm{L}$ at a $\mathrm{pH}$ of 7.4 and an observable wavelength maximum $\left(\lambda_{\max }\right)$ of $535 \mathrm{~nm}$. The calibration curve was linear for tryptophan concentrations between $10^{-6}$ and $10^{-3} \mathrm{~mol} / \mathrm{L}$ (1$1000 \mu \mathrm{mol} / \mathrm{L})$ with a correlation coefficient of 0.997 and this reagent combination was applied in the determination of tryptophan in samples. 


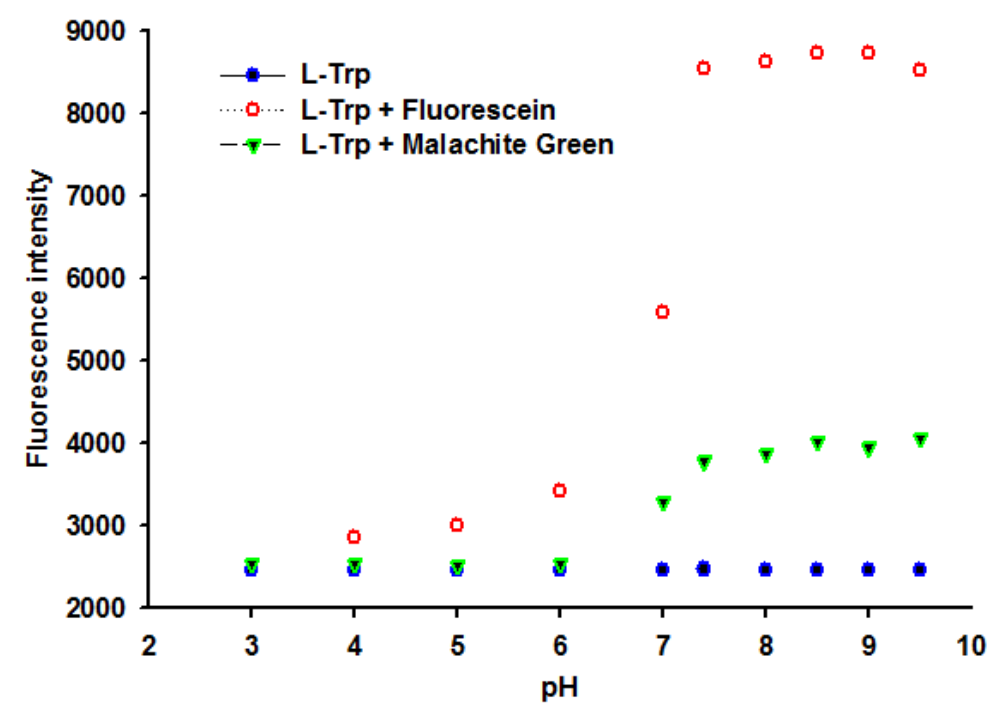

Fig. 1 - Effect of $\mathrm{pH}$ on the fluorescence intensity. The concentration of L-Tryptophan, Malachite Green, Fluorescein were $1.00 \times 10^{-4} \mathrm{~mol} / \mathrm{L}, 1.00 \times 10^{-3} \mathrm{~mol} / \mathrm{L}, 1.00 \times 10^{-3} \mathrm{~mol} / \mathrm{L}$ respectively.
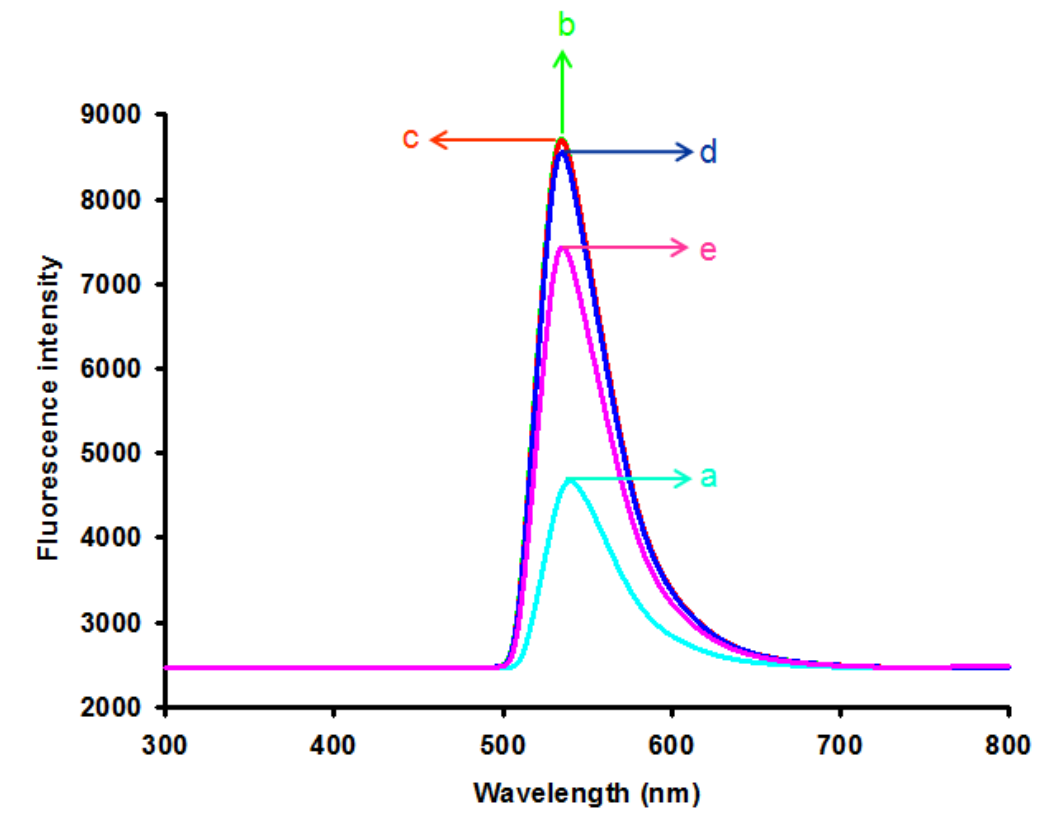

Fig. 2 - Overlay fluorescence spectra of mixed solutions (Conditions: $\mathrm{PBS} \mathrm{pH}=7.4$ ): (a) Fluorescein alone, $1.00 \times 10^{-3} \mathrm{~mol} / \mathrm{L}$, and also Fluorescein, $1.00 \times 10^{-3} \mathrm{~mol} / \mathrm{L}$ with: (b) L-Trp $1.00 \times 10^{-6} \mathrm{~mol} / \mathrm{L}$, (c) L-Trp $1.00 \times 10^{-5} \mathrm{~mol} / \mathrm{L}$, (d) L-Trp $1.00 \times 10^{-4} \mathrm{~mol} / \mathrm{L}$, and (e) L-Trp $1.00 \times 10^{-3} \mathrm{~mol} / \mathrm{L}$.

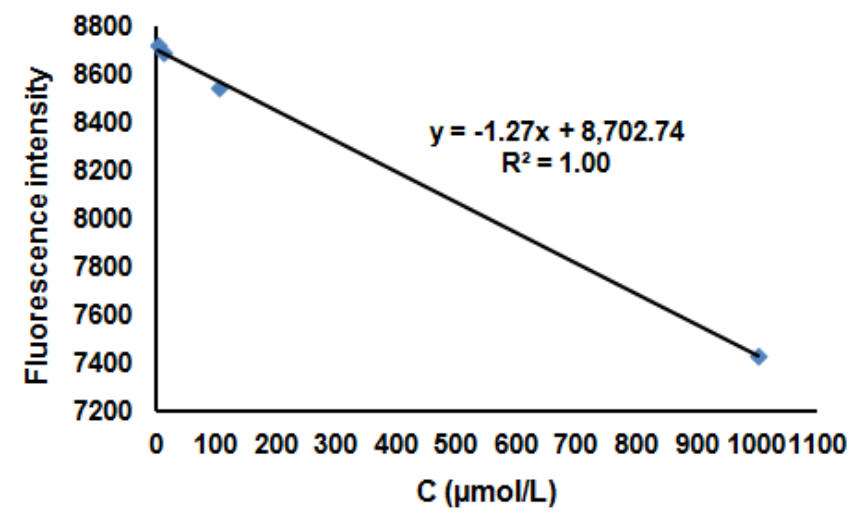

Fig. 3 - Calibration curve for L-Tryptophan solution. Conditions:

$\mathrm{L}-\operatorname{Trp} 1.00 \times 10^{-6} \mathrm{~mol} / \mathrm{L}$ to $1.00 \times 10^{-3} \mathrm{~mol} / \mathrm{L}$; Fluorescein $1.00 \times 10^{-3} \mathrm{~mol} / \mathrm{L} ; \mathrm{PBS} \mathrm{pH}=7.4$. 


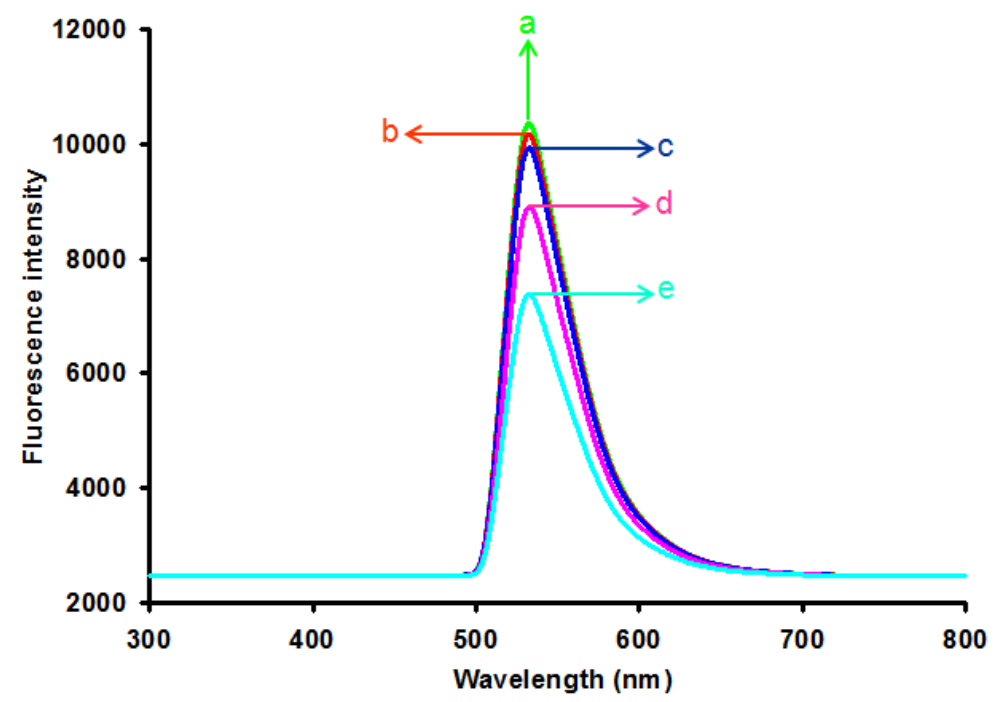

Fig. 4 - Overlay fluorescence spectra (Calibration graph) of different L-Tryptophan solutions in Fluorescein and $\mathrm{K}_{3} \mathrm{Fe}(\mathrm{CN})_{6}$ in PBS at a $\mathrm{pH}=7.4$ : (a) L-Trp $1.00 \times 10^{-6} \mathrm{~mol} / \mathrm{L}$, (b) L-Trp $1.00 \times 10^{-5} \mathrm{~mol} / \mathrm{L}$, (c) L-Trp $1.00 \times 10^{-4} \mathrm{~mol} / \mathrm{L}$, (d) L-Trp $5.00 \times 10^{-4} \mathrm{~mol} / \mathrm{L}$, and (e) L-Trp $1.00 \times 10^{-3} \mathrm{~mol} / \mathrm{L}$; Conditions: Fluorescein $1.00 \times 10^{-3} \mathrm{~mol} / \mathrm{L}, \mathrm{K}_{3} \mathrm{Fe}(\mathrm{CN})_{6} 1.00 \times 10^{-5} \mathrm{~mol} / \mathrm{L}$

\section{Table 1}

The tolerable concentration ratios of some interfering species to $1.00 \times 10^{-6} \mathrm{~mol} / \mathrm{L}$ tryptophan

\begin{tabular}{lc}
\hline \multicolumn{1}{c}{ Substance } & Tolerable concentration ratio \\
\hline D-Glucose & 1000 \\
L-Leucine & 1000 \\
L-Alanine & 500 \\
Uric acid & 500 \\
L-Phenylalanine & 100 \\
DL-Aspartic acid & 100 \\
L-Isoleucine & 100 \\
DL-Histidine & 100 \\
Ascorbic acid (Vitamin C) & 100 \\
L-Cysteine & 10 \\
Dopamine & 10 \\
D-Valine & 10 \\
L-Tyrosine & 10 \\
\hline
\end{tabular}

Table 2

Determination of tryptophan in pharmaceutical capsules

\begin{tabular}{cccc}
\hline Sample & $\begin{array}{c}\text { Amount labeled of tryptophan } \\
(\mathbf{m g} / \mathbf{m L})\end{array}$ & $\begin{array}{c}\text { Amount found of tryptophan } \\
(\mathbf{m g} / \mathbf{m L}) \pm \text { RSD (\%)* }\end{array}$ & $\begin{array}{c}\text { Recovery } \\
\mathbf{( \% )}\end{array}$ \\
\hline Product T1 & 15.00 & $15.42 \pm 0.07$ & 102.78 \\
Product T2 & 15.00 & $15.04 \pm 0.28$ & 100.29 \\
Product T3 & 15.00 & $15.03 \pm 0.23$ & 100.19 \\
Product T4 & 15.00 & $15.00 \pm 0.09$ & 100.00 \\
Product T5 & 15.00 & $14.99 \pm 0.08$ & 99.94 \\
\hline
\end{tabular}

*Relative standard deviation for 5 measurements $(n=5)$ 
Table 3

Determination of tryptophan in beer samples

\begin{tabular}{ccccc}
\hline Sample & $\begin{array}{c}\text { Added } \\
(\mathbf{m o l} / \mathbf{L})\end{array}$ & $\begin{array}{c}\text { Found } \\
(\mathbf{m o l} / \mathbf{L})\end{array}$ & Recovery (\%) & RSD (\%)* \\
\hline Beer 1 : tryptophan & $1.00 \times 10^{-5}$ & $1.43 \times 10^{-5}$ & 93.65 & 0.28 \\
Beer 2 : tryptophan & $1.00 \times 10^{-4}$ & $1.58 \times 10^{-4}$ & 94.24 & 0.01 \\
Beer 3 : tryptophan & $5.00 \times 10^{-4}$ & $9.29 \times 10^{-4}$ & 95.11 & 0.08 \\
\hline
\end{tabular}

* Relative standard deviation for 5 measurements $(\mathrm{n}=5)$

\section{Interference studies}

In order to assess the selectivity of the developed method, the interference of various species and excipients commonly used in pharmaceutical formulations was evaluated by analyzing a standard solution containing $1.00 \times 10^{-}$ ${ }^{6} \mathrm{~mol} / \mathrm{L}$ tryptophan and different amounts of each of the coexisting species. The tolerated limit for a foreign species was taken as the largest amount yielding a relative error less than $5 \%$ for the determination of tryptophan. The results of interference tests are summarized in Table 1. They show that the proposed method is very selective.

\section{Analytical Applications}

The proposed enhancement tryptophan-fluorescence method using fluorescein as fluorescent dye and $\mathrm{K}_{3} \mathrm{Fe}(\mathrm{CN})_{6}$ as oxidant was applied for the determination of tryptophan in pharmaceutical capsules and beer. The results are given in Table 2 for pharmaceutical capsules and in Table 3 for beer. As shown in Table 2 the recoveries agreed very well with the certified amount labeled for tryptophan in the pharmaceutical capsules with very good recoveries between 99.9 and $102.8 \%$ and a relative standard deviation (RSD\%) of less than $0.5 \%(\mathrm{n}=5)$. Furthermore as outlined in Table 3 the recoveries for the determination of tryptophan in beer were between 93.7 and $95.1 \%$ with a relative standard deviation $(\mathrm{RSD} \%)$ of less than $0.5 \%(n=5)$.

\section{CONCLUSIONS}

Tryptophan is an important intrinsic fluorescent substance (amino acid) that can be used to estimate the nature of the microenvironment of tryptophan and possible assay of tryptophan. However, the native fluorescence of tryptophan alone is not very sensitive and this limits the reliability of analytical methods for the determination of tryptophan. Various possibilities with a strategic study and evaluation were therefore investigated to get a stable and sustainable increase in the maximum response signal of tryptophan-fluorescence for proper determination of tryptophan. Fluorescein as fluorescent dye and $\mathrm{K}_{3} \mathrm{Fe}(\mathrm{CN})_{6}$ as oxidant successfully enhanced the tryptophan-fluorescence response signal to such an extent that a proposed enhancement tryptophan-fluorescence method using these inexpensive reagents was successfully applied for the determination of tryptophan in pharmaceutical capsules and beer with very good recoveries and relative standard deviation. Fluorescein and potassium hexacyanoferrate(III) reagents in this proposed method are commercially easy available and therefore the proposed method could be easily adopted to routine laboratories for the determination of tryptophan in pharmaceutical formulations and the beer industry.

Acknowledgements. The authors gratefully acknowledge the Roumanian National Authority for Scientific Research, UEFISCDI for financial support, under grants PN-II-ID-PCE2011-3-0538/2012-2014, financed by contract 100/27.10.2011 and PN-III-P4-ID-PCE-2016-0050.

\section{REFERENCES}

1. J. D. Fernstrom, Physiol. Rev., 1983, 63, 484-546.

2. J. D. Schaechter and R. J. Wurtman, Brain Res., 1990, 532, 203-210.

3. R. J. Wurtman and F. Anton-Tay, Recent Prog. Horm. Res. 1969, 25, 493-522.

4. M. Ikeda, H.Tsuji, S. Nakamura, A. Ichiyama, Y. Nishizuka and O. Hayaishi, J. Biol. Chem., 1965, 240, 1395-1401.

5. W. Kochen and H. Steinhart, "L-Tryptophan: Current prospects in medicine and drug safety", de-Gruyter, Berlin, 1994.

6. H. N. Noristani, A. Verkhratsky and J. J. Rodriguez, Aging Cell, 2012, 11, 810-822.

7. Y. Chen and G. J. Guillemin, Int. J. Tryptophan Res., 2009, 2, 1-19. 
8. R. S Grant, S. E. Coggan and G. A. Smythe, Int. J. Tryptophan Res., 2009, 2, 71-79.

9. Z. Chen, K. Okamura, M. Hanaki and T. Nagaoka, Anal. Sci., 2002, 18, 417-421.

10. A. R. Fiorucci and E. T. G. Cavalheiro, J. Pharm. Biomed. Anal., 2002, 28, 909-915.

11. V. I. Paz Zanini, R. E. Giménez, O. E. Linarez Pérez, B .A. López de Mishima and C. D. Borsarelli, Sens. Actuators B: Chem., 2015, 209, 391-398.

12. Y. V. Tcherkas, L. A. Kartsora and I. N. Krasnova, J. Chromatogr. A, 2001, 913, 303-308.

13. A. Alegria, R. Barbera, R. Farre, M. Ferreres, M. J. Lagarda and J. C. Lopez, J. Chromatogr. A, 1996, 721, 83-88.

14. W. Lian, D. J. Ma, X. Xu, Y. Chen and Y. L. Wu, J. Digest. Dis., 2012, 13, 100-106.

15. W. Zhu, A. Stevens, K. Dettmer, E. Gottfried, S. Hoves, M. Kreutz, E. Holler, A. B. Canelas, I. Kema and P. J. Oefner, Anal. Bioanal. Chem., 2011, 401, 3249-3261.

16. H. Li, F. Li, C. Han, Z. Cui, G. Xie and A. Zhang, Sens. Actuators B: Chem., 2010, 145, 194-199.

17. D. M. Reynolds, Water Res., 2003, 37, 3055-3060.
18. M. A. Malone, H. Zuo, S. M. Lunte and M. R. Smyth, J. Chromatogr. A, 1995, 700, 73-80.

19. C. Y. Gao, N. Chu and S. H. Fan, Anal. Lett., 2010, 43, 2142-2151.

20. F. Wu, B. Tong and Q. Zhang, Anal. Sci., 2011, 27, 529533.

21. J. T. Vivian and P. R. Callis, Biophys. J., 2001, 80, 20932109.

22. R. M. Watt and E. W. Voss, Jr., Immunochemistry, 1977, 14, 533-541.

23. N. Marme, J. P. Knemeyer, M. Sauer and J. Wolfrum, Bioconjugate Chem., 2003, 14, 1133-1139.

24. T. M. Togashi, B. Szezupak, A. G. Ryder, A. Calvet, M. O'Loughlin, J. Phys. Chem. A, 2009, 113, 2757-2767.

25. M. Schifferer-Waritschlager, "Development of fluorescent biosensors probing RNA function", PhD-Dissertation, Dissertation der Fakultät für Biologie der LudwigMaximilians-Universität München, Germany, 2011.

26. A. B. T Ghisaidoobe and S. J. Chung, Int. J. Mol. Sci., 2014, 15, 22518-22538. 